\title{
MEDIO SIGLO DE VIDA DE BYZANTION NEA HELLÁS
}

Hace 50 años, en octubre de 1970, apareció el primer número del anuario del llamado entonces Centro de Estudios Bizantinos y Neohelénicos, bajo la dirección y por iniciativa del profesor Fotios Malleros Kasimatis, fundador y primer director de esta unidad académica de la Facultad de Filosofía y Educación de la Universidad de Chile.

El cuidadoso proceso de edición de la revista estuvo a cargo del profesor Alejandro Zorbas Daskalakis y los artículos que integraron el volumen fueron aportados por los profesores Fotios Malleros, Héctor Herrera Cajas, Christos Clair Vasiliadis y Miguel Castillo Didier; por el escritor y estudioso griego Petros Jaris y por el Agregado de Prensa de la Embajada de Grecia don Gabriel Mustakis.

A través de cinco décadas, el anuario ha publicado trabajos de estudiosos de los más diversos países: Grecia. Chipre, Rumania, Suiza, Italia, Francia, España, Estados Unidos, México, Venezuela, Colombia, Brasil, Argentina, Uruguay.

El anuario tiene tres secciones de artículos: Grecia Antigua, Grecia Bizantina y Grecia Moderna; más secciones de textos, noticias, reseñas de libros.

Byzantion Nea Hellás llega a este aniversario con su número 39, de los cuales 20 están ya a la libre disposición de los estudiosos en el sitio https://byzantion.uchile.cl/index.php/RBNH/issue/archive, e indexado en Scopus, SciELO Chile, Redalyc, DOAJ, Latindex, Gale y Clase. En el sitio www.estudiosgriegos.cl pueden consultarse los índices de los 39 volúmenes.

Las tres secciones de artículos están dedicadas a la presentación de trabajos de investigación en las amplias áreas de la cultura griega antigua, medieval y moderna.

\section{Centro de Estudios Griegos, Bizantinos y Neohelénicos "Fotios Malleros"}

Facultad de Filosofía y Humanidades - Universidad de Chile. 